\title{
ISB News May 2011: From the President
}

\author{
Paul J. Beggs
}

(C) ISB 2011

The 19th International Congress of Biometeorology (ICB2011) is now only seven months away, and I expect many International Journal of Biometeorology readers will have submitted abstracts and are organising their flights to and accommodation in Auckland, New Zealand. An important date to keep in mind is 26 May 2011 which is the date for notification of abstract acceptance, and the date that ICB2011 author registration opens via the ICB2011 web site.

A limited number of Symposia, to be held as part of ICB2011, and related to the Congress theme of Climate and Society, are now being finalised and organised by their Chairs. Professor Tord Kjellstrom from the National Centre for Epidemiology and Population Health at The Australian National University, for example, is organising a sympo- sium on "Methods to Measure Hot Climate Impacts on Occupational Health", which will include leading international speakers in the field. Other symposia on phenology, management of extreme events, adaptation of livestock in relation to climate change, climate change and human health, and climate and tourism, are presently being negotiated with the respective proposers.

The ICB2011 web site is http://www.icb2011.com/. The International Society of Biometeorology web site, including the link to the ISB online membership application page, is http://www.biometeorology.org/. The Society, as always, welcomes new members in any of its membership categories: Regular, Student, Low and Middle Income Country, and Retired.
P. J. Beggs $(\bowtie)$

Department of Environment and Geography, Faculty of Science,

Macquarie University,

Sydney, Australia

e-mail: paul.beggs@mq.edu.au 